Federal Reserve Bank of Minneapolis

Research Department Staff Report 311

September 2002

\title{
Overturning Mundell: Fiscal Policy in a Monetary Union*
}

\author{
Russell Cooper \\ Boston University and Federal Reserve Bank of Minneapolis
}

Hubert Kempf

EUREQua, Université Paris-1 Panthéon-Sorbonne

\begin{abstract}
Central to ongoing debates over the desirability of monetary unions is a supposed trade-off, outlined by Mundell [1961]: a monetary union reduces transactions costs but renders stabilization policy less effective. If shocks across countries are sufficiently correlated, then, according to this argument, delegating monetary policy to a single central bank is not very costly and a monetary union is desirable.

This paper explores this argument in a setting with both monetary and fiscal policies. In an economy with monetary policy alone, we confirm the presence of the trade-off and find that indeed a monetary union will not be welfare improving if the correlation of national shocks is too low. However, fiscal interventions by national governments, combined with a central bank that has the ability to commit to monetary policy, overturn these results. In equilibrium, such a monetary union will be welfare improving for any correlation of shocks.
\end{abstract}

${ }^{*}$ We are grateful to the CNRS and the NSF for financial support. This is a much revised version of our working paper, Cooper and Kempf [2000]. The suggestions of two anonymous referees as well as the Managing Editor are appreciated. Comments from seminar participants at Boston College, Boston University, the Federal Reserve Bank of Cleveland, the Federal Reserve Bank of Minneapolis, McMaster University, the University of Pittsburgh, the European University Institute (Florence), CREST (INSEE), GREMAQ (Université de Toulouse), GREQAM (Université Aix-Marseille-II), Université de Lyon and EUREQua (Université Paris-1 Panthéon-Sorbonne) are gratefully acknowledged. The views expressed herein are those of the authors and not necessarily those of the Federal Reserve Bank of Minneapolis or the Federal Reserve System. 


\section{Overview}

Central to ongoing debates over the desirability and design of monetary unions is a supposed trade-off, outlined by Mundell [1961]: the gains to a monetary union arise from eliminating barriers to transactions while the costs reflect the reduced effectiveness of stabilization policy once monetary policy is delegated to a single central bank. ${ }^{1}$ Consequently, researchers study the correlation of shocks across economies in order to evaluate welfare gains from a monetary union. In his evaluation of the EMU, Feldstein [1997, p. 32] perfectly exemplifies this view:

My own judgement is that, on balance, a European Monetary Union would be an economic liability. The gains from reduced transaction costs would be small and might, when looked at from the global point of view, be negative. At the same time, EMU would increase cyclical instability, raising the cyclical unemployment rate.

This paper addresses two questions. Under what conditions does the Mundellian tradeoff exist? When is the correlation of shocks a useful metric for evaluating the welfare gains from a monetary union?

We argue that the emphasis on this trade-off is misplaced because it ignores the significance of fiscal policy in determining the welfare gains from a monetary union. While the high correlation of shocks across countries is a sufficient condition for the existence of net gains to a monetary union, this condition is not necessary. Instead, once national fiscal policies are properly taken into account, the trade-off between stabilization losses and transaction cost reductions from a common currency disappears. In fact, a monetary union may be welfare improving regardless of the correlation of shocks.

We study these issues in a multiple country, overlapping generations model. This model has two key ingredients which ultimately underlie our version of the Mundellian tradeoff. The first is risk sharing between unemployed and employed agents through unemployment insurance: this is the essence of "stabilization policy" in our environment. Whether there is a stabilization loss from a monetary union depends on how well these risks can be shared once monetary policy is delegated to a single central bank. Here the existence of country specific fiscal policy instruments is key. Second, to create potential gains to a monetary union from a reduction in trading frictions, there are agent specific taste shocks. As we shall see, these frictions can lead to a misallocation of resources in a multiple currency environment which is eliminated by a monetary union.

This approach is quite different from Mundell [1961], which stressed price inflexibility in a static economy without any explicit representation of welfare and without any recognition of the vital importance of the interactions between fiscal and monetary policies. Our

\footnotetext{
${ }^{1}$ These issues are paramount in the so-called Delors report (Emerson et al., [1992]), which provided the official arguments in favor of EMU. These same points reappear in the analysis of the proposed North American Monetary Union as discussed by Buiter [1999].
} 
framework is an explicit dynamic equilibrium structure which allows us to formally study these issues without assuming ad hoc decision rule for agents and policymakers. Further, we evaluate the welfare implications of a monetary union using the expected utility of agents in our economy.

To evaluate the gains to a monetary union, we first study the equilibria of a multiple currency version of our model. In this economy, governments facilitate risk sharing between agents through monetary policy. Essentially an inflation tax is used to finance unemployment insurance. However, the presence of multiple currencies creates distortions in ex post consumption allocations across households. Due to cash-in-advance constraints, households make portfolio decisions prior to the realization of their tastes. Consequently, there are ex post welfare improving reallocations of consumption that cannot be realized in the multiple currency setting.

We then consider a monetary union. The ex post distortions in consumption are eliminated by a monetary union because a common currency eliminates any portfolio choice. However, the delegation of monetary policy to a single central bank may be costly, as suggested by Mundell and the resulting literature, since stabilization policy may not be responsive enough to country specific circumstances. We find that only if shocks are sufficiently positively correlated across the countries will a monetary union increase welfare. This finding represents a formalization of the Mundellian trade-off but, notably, in an environment with flexible prices and stabilization policy through the provision of unemployment insurance.

Once fiscal policy is properly incorporated into the analysis, the trade-off vanishes. More precisely, suppose the common monetary authority has the ability to act prior to national fiscal authorities. This strong central bank has commitment power vis-a-vis the national fiscal authorities. If the central bank holds the money supply constant and fiscal policy is used for internal stabilization, then risks are efficiently allocated within and across economies. Thus, the transactions gains to a common currency are realized without a stabilization loss. A monetary union is welfare increasing regardless of the correlation of shocks.

We consider two extensions of the model to assess the robustness of these results. The first extension introduces price rigidity. This allows us to study the role of stabilization policy in terms of government actions to influence the levels of output and employment rather than its distribution between employed and unemployed agents. Here we confirm our findings: with adequate fiscal national policies, the Mundellian trade-off is not present, and a monetary union is welfare improving. We then use this structure to discuss a more general theme concerning the relationship between the imperfections to be addressed through stabilization policy and the set of tools available to policymakers.

In the second extension, we dramatically weaken the commitment power of the single central bank: it is compelled to monetize the deficits of the independent fiscal authorities. ${ }^{2}$

\footnotetext{
${ }^{2}$ Chari and Kehoe [1998] also point to the importance of commitment issues between members of a monetary union using a two-period reduced form model with government debt and money.
} 
As a consequence, each member country forces money creation by the central bank as a means of financing its fiscal deficit. The interaction between national governments leads to excessive inflation because each country uses its fiscal policy to induce an inflation tax on the other. In equilibrium, a monetary union can reduce welfare relative to a world economy with multiple currencies.

This illustrates that the net gains to a monetary union will depend on the design of fiscal and monetary institutions. Put differently, having a wide range of independent fiscal instruments may not be sufficient: incentives for the appropriate use of these tools must be present within the monetary union to achieve welfare improving allocations. The potential loss from a monetary union due to its improper design is independent of the correlation of shocks.

\section{Economy without a Monetary Union}

The starting point for our analysis is a multiple currency world economy in which monetary policy is determined by each national government independently. This forms a benchmark to which we can compare the allocations obtained under a monetary union.

\section{A. Preference and Technology}

All agents live for two periods and reside in one of two countries. By assumption, labor is immobile. ${ }^{3}$ In each country, a single, non-storable good is produced. Agents work in youth, producing the country specific good, and consume the goods produced in both countries in old age.

Agents differ within countries due to their employment status: each period a random fraction $q_{t}$ of them in the home country have an employment opportunity while the remainder are unable to produce. This device allows us to include real shocks to the model and motivates government intervention through the provision of unemployment insurance. ${ }^{4}$ Thus we initially focus on government's facilitating risk sharing between employed and unemployed agents. We assume that $q_{t}$ is a serially uncorrelated shock with $E\left[q_{t}\right]=\bar{q} \in(0,1){ }^{5}$

With regard to their preferences, agents consume the good produced at home and the one produced abroad. As in Cooper and Kempf [forthcoming], we introduce individual specific shocks into preferences to motivate the gains from a monetary union, discussed in the next sections. More formally, generation $t$ individuals in the home country have preferences

\footnotetext{
${ }^{3}$ Thus, relative to the discussion in Mundell [1961], our results are biased against finding gains to a monetary union.

${ }^{4}$ Clearly this is just one of a multitude of possible shocks. This specification was chosen partly for tractability and partly due to the fiscal obligation that arises from the provision of unemployment insurance, a natural and quite visible form of stabilization policy. We study stabilization policy without risk sharing in Section 5 .

${ }^{5}$ Throughout, we refer directly to home country variables and denote those for the foreign country with * superscripts. Throughout the paper, unless specifically noted otherwise, there are analogous expressions for the foreign country.
} 
represented by

$$
U^{i h}=U\left(c_{t+1}^{i h}, c_{t+1}^{i f}, n_{t}^{i}, \theta_{t+1}\right)=\theta_{t+1} \ln \left(c_{t+1}^{i h}\right)+\left(1-\theta_{t+1}\right) \ln \left(c_{t+1}^{i f}\right)-g\left(n_{t}^{i}\right)
$$

The superscript $i$ corresponds to the status of the agent, whether she is employed $(i=E)$ or unemployed $(i=U), c_{t+1}^{i h}$ is the level of consumption of the home good when agents are old, and $c_{t+1}^{i f}$ is the level of consumption of the foreign good when agents are old, and $n_{t}^{i}$ is the supply of labor by agent $i$, necessarily equal to zero if $i=U$. The function $g(\cdot)$ represents the disutility of work and is assumed to be increasing, convex and continuously differentiable.

Finally, $\theta_{t+1} \in[0,1]$ is an iid random variable with mean $\bar{\theta}$. It represents an individual specific taste shock and thus influences the marginal rate of substitution between home and foreign goods of generation $t$ in period $t+1$. The taste shock is realized in period $t+1$. A similar individual specific shock occurs in the foreign country with the same mean. These preference shocks are uncorrelated across countries, agents and time.

The output of the representative agent is $n_{t}$, the same as the agent's labor input. Because agents are identical at the time of their labor supply decision, they will work the same amount. Hence per capita output of the home good in period $t$ is $n_{t} q_{t}$.

\section{B. Individual Optimization}

The timing of decisions within a period is summarized in Figure 1. A young employed agent in the home (foreign) country makes a labor supply decision and sells the output to old agents from both countries in exchange for home (foreign) currency. Young unemployed agents receive income from unemployment insurance. The home (foreign) young agents take the home (foreign) currency and exchange part of it for foreign (home) currency. These decisions are made without knowing the realized value of their individual tastes, $\theta_{t+1}$. In the next period, the agent is old, and her tastes are revealed. At that point, her portfolio of currencies is used to finance consumption of the home and foreign goods. ${ }^{6}$

The representative agent's choices over employment and consumption goods must satisfy a budget and a pair of cash-in-advance constraints. We assume that goods produced in one country must be purchased in that country's currency. The constraints of a home agent are given by

$$
m_{t}^{i h}+e_{t} m_{t}^{i f}=I_{t}^{i}
$$

\footnotetext{
${ }^{6}$ In our framework, the cost of going to an exchange market for old agents is thus infinite. As we shall see, the implications of this infinite cost can be parameterized by the uncertainty over tastes. Cooper and Kempf [forthcoming] argue that the cash-in-advance constraints can be generated endogenously by allowing individual governments to choose legal restrictions regarding the type of currency used in their home markets. Here, for tractability, we impose these constraints directly. Notable contributions by Lucas [1990], Fuerst [1992] and Christiano and Eichenbaum [1992] also use a particular sequencing of exchanges to limit transactions through the introduction of costly market participation. Finally, the assumption about the impossibility of returning to the exchange market could be relaxed, without modifying our qualitative results. See Chatterjee and Corbae [1992] and Alvarez et al. [2000] for developments along these lines.
} 
Figure 1: Period $t$

Generation $t$ young

employed produce $n$

employed sell goods to old

exchange income for currencies

\begin{tabular}{|c|} 
\\
\hline taste shock \\
$\theta_{t}$ realized
\end{tabular}

unemployed collect UI

buy goods

consume; die

Generation $t-1$ old

and

$$
p_{t+1} c_{t+1}^{i h}=m_{t}^{i h} \quad p_{t+1}^{*} c_{t+1}^{i f}=m_{t}^{i f}
$$

for $i=E, U$. Here $I_{t}^{i}$ is the income, and $m_{t}^{i h}$ and $m_{t}^{i f}$ represent the holdings of home and foreign currency by a home agent of generation $t$ with employment status $i=E, U$.

The period $t$ prices of home (foreign) goods expressed in the home (foreign) currencies are given by $p_{t}$ and $p_{t}^{*}$, respectively, and $e_{t}$ is the period $t$ price of foreign currency in terms of home currency. From (2), income earned in youth is held as either home currency or foreign currency. Equations (3) relate the holdings of the different currencies to the consumption of final goods and thus reflect the cash-in-advance constraints.

The representative young, employed, generation $t$ home agent solves

$$
\max _{c_{t+1}^{E h}, c_{t+1}^{E f}, n_{t}} E\left\{\theta_{t+1} \ln \left(c_{t+1}^{E h}\right)+\left(1-\theta_{t+1}\right) \ln \left(c_{t+1}^{E f}\right)\right\}-g\left(n_{t}\right)
$$

subject to (2), (3) and $I_{t}^{E}=p_{t} n_{t}$. The representative young, unemployed, generation $t$ home agent solves the same problem with $n_{t}=0$ and income given by $I_{t}^{U}=b_{t}$, where $b_{t}$ is the nominal unemployment benefit paid to an unemployed agent. Expectations are with respect to the taste shock, $\theta_{t+1}$, as well as future prices, $p_{t+1}$ and $p_{t+1}^{*}$.

As shown in the proof of Proposition 1, the first-order conditions imply

$$
m_{t}^{i h}=\bar{\theta} I_{t}^{i} \quad \text { and } \quad m_{t}^{i f}=(1-\bar{\theta}) I_{t}^{i} / e_{t} .
$$

From (3), these money holdings imply consumption levels of

$$
c_{t+1}^{i h}=\frac{\bar{\theta} I_{t}^{i}}{p_{t+1}} \quad \text { and } \quad c_{t+1}^{i f}=\frac{(1-\bar{\theta}) I_{t}^{i}}{e_{t} p_{t+1}^{*}}
$$

for $i=E, U$. Further, the representative generation $t$ employed agent's choice of employment 
satisfies

$$
1=n_{t} g^{\prime}\left(n_{t}\right)
$$

Given the assumed log-linear utility functions, individual labor supply decisions are independent of the real returns to work. Denote by $\bar{n}$ the level of labor that solves (7).

In this economy, government policy is reduced to the determination of the benefits paid to the unemployed and their financing. Assume that the transfers to the unemployed must be financed by the printing of money. So the budget constraint for the home government is

$$
M_{t+1}-M_{t}=\left(1-q_{t}\right) b_{t}
$$

where $M_{t}$ is the period $t$ stock of fiat currency in the home country.

\section{Market Equilibrium Given Government Policies}

In each period, a goods market and a money market open in each of the two countries. The market clearing conditions for the good markets, home and abroad, respectively, in period $t+1$ are

$$
\begin{aligned}
& q_{t+1} \bar{n}=q_{t} c_{t+1}^{E h}+\left(1-q_{t}\right) c_{t+1}^{U h}+q_{t}^{*} c_{t+1}^{* E h}+\left(1-q_{t}^{*}\right) c_{t+1}^{* U h} \\
& q_{t+1}^{*} \bar{n}=q_{t}^{*} c_{t+1}^{* E f}+\left(1-q_{t}^{*}\right) c_{t+1}^{* U f}+q_{t} c_{t+1}^{E f}+\left(1-q_{t}\right) c_{t+1}^{U f} .
\end{aligned}
$$

The left side of these expressions is the output by employed agents in period $t+1$. The right side corresponds to spending on home (foreign) goods by the four types of old agents: employed and unemployed in each of the two countries.

For the money markets, the given stock of fiat money must be held. ${ }^{7}$ For the home and foreign countries this implies

$$
\begin{aligned}
M_{t} & =p_{t} q_{t} \bar{n}=q_{t} m_{t}^{E h}+\left(1-q_{t}\right) m_{t}^{U h}+q_{t}^{*} m_{t}^{* E h}+\left(1-q_{t}^{*}\right) m_{t}^{* U h} \\
M_{t}^{*} & =p_{t}^{*} q_{t}^{*} \bar{n}=q_{t} m_{t}^{E f}+\left(1-q_{t}\right) m_{t}^{U f}+q_{t}^{*} m_{t}^{* E f}+\left(1-q_{t}^{*}\right) m_{t}^{* U f} .
\end{aligned}
$$

The exchange market clearing condition is

$$
q_{t}^{*} m_{t}^{* E h}+\left(1-q_{t}^{*}\right) m_{t}^{* U h}=e_{t}\left(q_{t} m_{t}^{E f}+\left(1-q_{t}\right) m_{t}^{U f}\right) .
$$

The allocation given government policies is characterized by

Proposition 1.. In a world economy with multiple currencies, given government unemploy-

\footnotetext{
${ }^{7}$ We give two versions of this condition. The first holds at the time goods markets close, where the stock of home (foreign) fiat money is held by young home (foreign) agents. The second version holds once exchange markets open, where the stock of home (foreign) fiat money is held by both home and foreign agents.
} 
ment benefits, home consumption allocations are given by

$$
\begin{aligned}
c_{t+1}^{E h} & =\bar{\theta} \cdot \frac{q_{t+1}}{q_{t}} \cdot \frac{1}{1+\mu_{t}^{F}} \cdot \bar{n}, \quad c_{t+1}^{E f}=(1-\bar{\theta}) \cdot \frac{q_{t+1}^{*}}{q_{t}} \cdot \frac{1}{1+\mu_{t}^{F}} \cdot \bar{n} \\
c_{t+1}^{U h} & =\bar{\theta} \cdot \frac{q_{t+1}}{1-q_{t}}\left(\frac{\mu_{t}^{F}}{1+\mu_{t}^{F}}\right) \bar{n}, \quad c_{t+1}^{U f}=(1-\bar{\theta}) \cdot \frac{q_{t+1}^{*}}{1-q_{t}}\left(\frac{\mu_{t}^{F}}{1+\mu_{t}^{F}}\right) \bar{n} .
\end{aligned}
$$

Proof. See the Appendix.

A similar proposition holds for the foreign consumption allocations. In these expressions, the rate of growth of the home money supply, $\left(\frac{M_{t+1}-M_{t}}{M_{t}}\right)$, is denoted by $\mu_{t}^{F}$ and is linked to unemployment benefits by (8).

The home agent's consumption of home and foreign goods depends on employment status in youth, the employment rate in youth $\left(q_{t}\right)$ as well as on the employment rate in both countries $\left(q_{t+1}, q_{t+1}^{*}\right)$ during old age. Insurance may be provided to offset these disturbances through the judicious choice of monetary policy.

\section{Equilibrium Monetary Policies}

Governments act noncooperatively vis-a-vis one another. Their objective is to maximize the expected lifetime utility of a representative young agent in the agent's own country. Governments choose money creation rates simultaneously each period, after observing the fraction of people currently employed and taking as given the policy choices of the other government. ${ }^{8}$ Specifically, given $\mu_{t}^{* F}$ and the realized values of $\left(q_{t}, q_{t}^{*}\right)$, the home government solves

$$
\max _{\mu_{t}^{F}} E_{\left(\theta, q_{t+1}, q_{t+1}^{*}\right)}\left[q_{t} U\left(c_{t+1}^{E h}, c_{t+1}^{E f}, \bar{n}, \theta_{t+1}\right)+\left(1-q_{t}\right) U\left(c_{t+1}^{U h}, c_{t+1}^{U f}, 0, \theta_{t+1}\right)\right]
$$

where the consumption levels are from Proposition 1 and $\bar{n}$ solves (7). From Proposition 1 , the consumption levels of home agents are independent of $\mu_{t}^{* F}$. Thus there is no interaction between the governments. The equilibrium of the noncooperative game is characterized by

Proposition 2.. In a world economy with flexible exchange rates and multiple currencies, the equilibrium money creation rates satisfy

$$
\frac{1}{1+\mu_{t}^{F}}=q_{t}, \frac{1}{1+\mu_{t}^{* F}}=q_{t}^{*}
$$

Proof. See the Appendix.

The optimal policy is thus countercyclical: in periods of high unemployment, tranfers are larger and thus so is the inflation tax. Using the optimal policies, equilibrium consumption

\footnotetext{
${ }^{8}$ The money supplies in each country are the only state variables in the system because there is no physical capital. The equilibria that we characterize are dependent only on the country specific employment rates and are Markov perfect given this representation of the state space. Note that these restrictions seem natural given that the inherited stocks of fiat money in each country are, in the equilibria we consider, irrelevant for real allocations. Of course, there may exist other equilibria in which inherited money stocks matter.
} 
allocations are obtained by substituting (17) into (14) and (15), yielding

$$
c_{t+1}^{E h}=c_{t+1}^{U h}=\bar{\theta} q_{t+1} \bar{n} \quad \text { and } \quad c_{t+1}^{E f}=c_{t+1}^{U f}=(1-\bar{\theta}) q_{t+1}^{*} \bar{n}
$$

and

$$
c_{t+1}^{* E h}=c_{t+1}^{* U h}=(1-\bar{\theta}) q_{t+1} \bar{n} \quad \text { and } \quad c_{t+1}^{* E f}=c_{t+1}^{* U f}=\bar{\theta} q_{t+1}^{*} \bar{n} .
$$

The optimal noncooperative government policies perfectly insure agents from the current risk of unemployment; consumption levels are independent of employment status in youth. This is achieved by using money creation to ensure that the nominal incomes of agents within a country are equal $\left(I_{t}^{E}=I_{t}^{U}\right)$, regardless of their employment status. However, consumption does not vary with the realized values of the taste shock.

Using these expressions for consumption allocations, the expected utility (denoted $V_{F}$ ) generated by this equilibrium is

$V_{F}=E\left(\theta_{t+1} \ln (\bar{\theta})+\left(1-\theta_{t+1}\right) \ln (1-\bar{\theta})\right)+\bar{\theta} E \ln \left(q_{t+1}\right)+(1-\bar{\theta}) E \ln \left(q_{t+1}^{*}\right)+\ln (\bar{n})-\bar{q} g(\bar{n})$

Here the expectation is taken with respect to the individual specific taste shock $\theta_{t+1}$ and to the employment shocks during the agent's old age $\left(q_{t+1}, q_{t+1}^{*}\right)$.

\section{E. Planner's Problem}

The inefficiencies generated by the presence of multiple currencies and the cash-inadvance constraints can be seen when the allocation is compared to that obtained by a planner. The central planner maximizes an ex ante weighted average of the welfare of the agents in each generation and in each country. Because the countries are completely symmetric, the planner gives equal weight to each. Further, we assume that the planner treats each generation equally. ${ }^{9}$ Since there is no physical capital and preferences are intertemporally separable, we look at allocations within a period where the planner decides on the employment levels of generation $t$ agents and the consumption levels for generation $t-1$ agents. In doing so, the planner conditions the allocation on the current state of the economy, including the realized tastes for each agent and the employment rates in the two countries. As characterized in Cooper and Kempf [2000], the solution to the planner's problem entails

- optimal risk sharing: any two old agents with the same realization of tastes should consume identical consumption bundles independent of nationality or employment status, and

- efficient employment: employment varies with $q\left(q^{*}\right)$ in order to stabilize total output. The efficient employment level solves

$$
g^{\prime}(n) n q=1=g^{\prime}\left(n^{*}\right) n^{*} q^{*} .
$$

\footnotetext{
${ }^{9}$ Thus the model abstracts from any political considerations that might lead to unequal treatment of countries and/or generations.
} 
In contrast to the equilibrium allocation in an environment with multiple currencies, in the planner's solution consumption is dependent upon the realized taste shock. It is in this sense that multiple currencies lead to the misallocation of resources, and thus there is a potential gain from a monetary union.

There is another difference between the equilibrium and efficient allocations. In the decentralized equilibrium, the labor supply of the home (foreign) agents is independent of $q\left(q^{*}\right)$ because the Cobb-Douglas preferences imply that this decision is independent of the real wage. In the planner's solution, employment varies with $q\left(q^{*}\right)$ in order to stabilize total output.

\section{A Mundellian Monetary Union}

We now consider a monetary union defined by the presence of a single currency and a single monetary authority which represents the interests of agents in member countries. The next subsection studies individual optimization. We then turn to the determination of monetary policy and a welfare evaluation of a monetary union. We term this a Mundellian monetary union because it formalizes the basic claim from Mundell [1961]: in a monetary union, the delegation of monetary policy can reduce transactions costs, but stabilization policy may be less effective.

\section{A. Individual Optimization}

In contrast to the world economy with multiple currencies, in a monetary union agents do not have to make currency portfolio decisions prior to the realization of their taste shocks. It is precisely the relaxation of the cash-in-advance constraints that leads to the gains associated with a monetary union. The representative young, employed, generation $t$ home agent solves

$$
\max _{\substack{E h, c_{t+1}^{E f}, c_{t+} \\ c_{t+1}}} E\left\{\theta_{t+1} \ln \left(c_{t+1}^{E h}\right)+\left(1-\theta_{t+1}\right) \ln \left(c_{t+1}^{E f}\right)\right\}-g\left(n_{t}\right)
$$

subject to

$$
p_{t+1} c_{t+1}^{E h}+p_{t+1}^{*} c_{t+1}^{E f}=p_{t} n_{t} \equiv I_{t}^{E} .
$$

In the budget constraint, $p_{t}\left(p_{t}^{*}\right)$ represents the period $t$ price of home (foreign) goods in terms of the common currency. The first order conditions for the representative, employed home agent are given by

$$
g^{\prime}\left(n_{t}\right) n_{t}=1
$$

and

$$
c_{t+1}^{E h}=\theta_{t+1} \frac{I_{t}^{E}}{p_{t+1}} \quad \text { and } \quad c_{t+1}^{E f}=\left(1-\theta_{t+1}\right) \frac{I_{t}^{E}}{p_{t+1}^{*}} .
$$

Equation (24) implies a constant labor supply equal to that obtained in the previous case, $\bar{n}$. Since the consumption decision is made after the realization of the taste shock, consumption levels respond to this shock. This points to an important welfare gain from a monetary 
union: the agent's portfolio of currency is more liquid, so consumptions can respond to agents' individual tastes.

The consumption levels for the representative unemployed agent satisfy

$$
c_{t+1}^{U h}=\theta_{t+1} \frac{I_{t}^{U}}{p_{t+1}} \quad \text { and } \quad c_{t+1}^{U f}=\left(1-\theta_{t+1}\right) \frac{I_{t}^{U}}{p_{t+1}^{*}}
$$

Since these agents are unemployed, their nominal incomes are equal to the unemployment benefits they receive from their national fiscal authority, denoted $b_{t}^{M}$.

\section{B. Monetary Policy and Equilibrium Allocation}

The central monetary authority creates money in period $t$ which is equally distributed to the fiscal authorities of the two governments. ${ }^{10}$ Because there is no direct taxation, these transfers from the central bank finance the unemployment benefits, $b_{t}^{M}$. So, the budget constraint of the home fiscal authority is given by

$$
\left(1-q_{t}\right) b_{t}^{M}=\Delta_{t}^{M}
$$

where $\Delta_{t}^{M}$ is the transfer to the home government from the monetary authority.

Clearly, the creation of a Mundellian monetary union restricts the unemployment insurance scheme of each country. But, from (25) and (26), consumption levels do depend on realizations of the taste shock. ${ }^{11}$ Is this monetary union desirable relative to a world economy with multiple currencies? We find

Proposition 3.. In a Mundellian monetary union, (i) if shocks are sufficiently correlated across countries and tastes are sufficiently variable, then the monetary union allocation will yield higher expected utility than the outcome with multiple currencies and (ii) if employment shocks are not perfectly positively correlated and taste shocks are not sufficiently variable, then the monetary union will not be welfare improving.

Proof. See the Appendix.

If shocks are perfectly correlated, the delegation of monetary policy is not costly since the single central bank has an incentive and the ability to replicate the policies that would have been undertaken by the individual governments. Given that the single currency eliminates the ex post misallocation of consumption, a monetary union is welfare improving. If $\operatorname{corr}\left(q_{t}, q_{t}^{*}\right) \neq$ 1 , then there is clearly a loss in stabilization from the creation of a monetary union. In this case, the Mundellian trade-off emerges: there are liquidity gains from a monetary union that

\footnotetext{
${ }^{10}$ By constraining monetary policy in this way, we distinguish it from a form of fiscal federalism. Further, as suggested by a referee, this policy is consistent with an open-market policy because it does not discriminate among participants in the money market.

${ }^{11} \mathrm{Or}$, if there were transactions costs associated with currency exchanges, we would find that the monetary union would eliminate them.
} 
are increasing in the variability of the taste shocks and stabilization losses that depend on $\operatorname{corr}\left(q_{t}, q_{t}^{*}\right)$.

As suggested by Mundell, these considerations lead to predictions about which types of economies are natural candidates for a monetary union. Economies with positively correlated shocks which trade with one another (so that there are indeed gains from the reduction of transactions costs) will profit from a monetary union. But the correlation of shocks is not the only issue. The potential role of fiscal policy as a tool for stabilization must also be considered.

\section{Fiscal Policy in a Monetary Union}

We supplement the model of a monetary union to allow each government another tool: a proportional income tax. The income tax provides a basis for financing unemployment insurance. In this case, a monetary union is welfare improving regardless of the correlation of shocks.

\section{A. Individual Optimization}

The presence of an income tax only slightly modifies our analysis of individual behavior. The income of an employed agent is

$$
p_{t} n_{t}\left(1-\tau_{t}^{S}\right) \equiv I_{t}^{E}
$$

where $\tau_{t}^{S}$ is the income tax on period $t$ employed workers. With this modification to $I_{t}^{E}$, the demand functions for both employed and unemployed agents are given by (25) and (26), respectively, and labor supply is determined from (24).

\section{B. Government Budget Constraints}

Of course, the budget constraints of the governments are modified to reflect the availability of income tax revenues. The budget constraint of the home fiscal authority is given by

$$
\left(1-q_{t}\right) b_{t}^{S}=\tau_{t}^{S} \bar{n} p_{t} q_{t}+\Delta_{t}^{S}
$$

where, as before, the monetary transfers to the fiscal authorities, $\left(\Delta_{t}^{S}\right)$, are constrained to be equal.

There are now three government entities: a single central bank and two national fiscal authorities. Importantly, these entities are linked: from (29), the set of feasible actions, $\left(b_{t}^{S}, \tau_{t}^{S}\right)$, of the home government depends on the transfers of the central bank. Within each period, the central bank moves first and decides upon the transfers that will be made to the individual governments. Given these transfers, the national governments noncooperatively choose $\left(b_{t}^{S}, \tau_{t}^{S}\right)$ to maximize the expected utility of a representative agent in their country, subject to (29). We term this a strong central bank, reflecting the commitment power of the monetary authority vis-a-vis the fiscal authorities and call this monetary arrangement a strong monetary union. We consider the alternative case in which the fiscal authorities 
move prior to the monetary authority in Section 5 .

\section{Equilibrium with a Strong Central Bank}

An equilibrium of the game between the central bank and the fiscal authorities is a set of state contingent national policies $\left(\tau_{t}^{S}, b_{t}^{S}, \tau_{t}^{* S}, b_{t}^{* S}\right)$ for the home and foreign governments and a level of monetary transfers from the central government to each government, $\Delta_{t}^{S}$. These period $t$ policies can be contingent upon the realized employment shocks $\left(q_{t}, q_{t}^{*}\right) .{ }^{12}$ In the second stage within each period, we find that the fiscal authorities, given transfers from the monetary authority, will optimally set unemployment insurance (UI) benefits to equate the incomes of employed and unemployed agents. ${ }^{13}$ Taking these decision rules by the fiscal authorities as given, the monetary authority can use money creation to finance these UI programs. However, in equilibrium, we find that active intervention by the central monetary authority is not required.

Proposition 4.. There exists an equilibrium in the strong monetary union where the rate of money creation is zero, irrespective of the values of the shocks, and the taxation rates are equal to

$$
\tau_{t}^{S}=1-q_{t} \quad \tau_{t}^{* S}=1-q_{t}^{*}
$$

The consumption allocations are given by

$$
\begin{aligned}
c_{t+1}^{E h} & =c_{t+1}^{U h}=\theta_{t+1} q_{t+1} \bar{n} \quad \text { and } \quad c_{t+1}^{E f}=c_{t+1}^{U f}=\left(1-\theta_{t+1}\right) q_{t+1}^{*} \bar{n} \\
c_{t+1}^{* E h} & =c_{t+1}^{* U h}=\left(1-\theta_{t+1}^{*}\right) q_{t+1} \bar{n} \quad \text { and } \quad c_{t+1}^{* E f}=c_{t+1}^{* U f}=\theta_{t+1}^{*} q_{t+1}^{*} \bar{n} .
\end{aligned}
$$

Employment satisfies $n=n^{*}=\bar{n}$ where

$$
g^{\prime}(\bar{n}) \bar{n}=1
$$

Proof. See the Appendix.

Note that the consumption levels for each type of agent depend on the ex post realization of the individual specific taste shock. This dependence of consumption on $\theta_{t+1}$, as in the Mundellian monetary union and the planner's allocation, is again one of the benefits of a common currency.

A very important aspect of the resulting allocation is that agents' nominal income levels are independent of both their individual employment status and country specific shocks to employment rates $\left(q_{t}, q_{t}^{*}\right)$ in their youth. This insurance was not present in the Mundellian monetary union except for the extreme case of perfectly correlated shocks.

\footnotetext{
${ }^{12}$ Again, because there are no physical state variables other than fiat money, we focus on equilibria of the infinite horizon economy in which the governments' interaction within each period is completely static.

${ }^{13}$ This is argued formally in the proof of Proposition 4. This insurance of nominal incomes underlies the real allocations characterized by (18) and (19) as well.
} 
The first form of insurance is provided directly by the taxation policy of the fiscal authorities. In the world economy with multiple currencies, the independent monetary authorities financed UI benefits with seignorage. In this monetary union, the addition of fiscal instruments allows this form of risk sharing.

The second form of insurance is provided by the stabilization of nominal incomes in response to the supply side employment shocks. Given the unitary elasticity of demand, created by the log-linear preferences, variations in prices effectively offset the exogenous variations in employment rates, leaving the nominal income earned by young employed agents independent of $q_{t}{ }^{14}$ If, as we assume, the money supply is equally distributed across the two countries in the initial period, then the young agents in each country will have equal shares of the money supply in all time periods. This guarantees that their nominal incomes are stabilized in the equilibrium with zero money growth.

As shown in Cooper-Kempf [2000], there are other stationary equilibria under a strong monetary union. In particular, if the lower support of the country specific employment shocks is sufficiently large, there will exist equilibria with positive money creation along with positive state contingent income taxes. To guarantee that nominal incomes are equal across countries, the nominal transfers to each country will be identical. Importantly, all of these equilibria support the same real allocations of consumption and employment.

In the equilibrium characterized by Proposition 4, the welfare of the representative agent is

$V_{S} \equiv E\left\{\theta_{t+1} \ln \left(\theta_{t+1}\right)+\left(1-\theta_{t+1}\right) \ln \left(1-\theta_{t+1}\right)\right\}+\bar{\theta} E \ln \left(q_{t+1}\right)+(1-\bar{\theta}) E \ln \left(q_{t+1}^{*}\right)+\ln (\bar{n})-\bar{q} g(\bar{n})$

\section{Welfare Comparisons}

The comparison of the allocation under a strong monetary union with that under multiple currencies is informative since it provides guidance on whether a monetary union is welfare improving relative to the status quo of multiple currencies. We saw earlier that without fiscal policy, the delegation of monetary policy to a single central bank could be undesirable if employment shocks were not sufficiently correlated. However, in the presence of fiscal policy instruments, we find that the Mundellian trade-off disappears:

Proposition 5.. The difference in expected utilities achieved in a strong monetary union and a flexible exchange rate world economy with multiple currencies is always positive and equals

$$
\begin{aligned}
\Lambda_{S F} & \equiv V_{S}-V_{F}=E\left\{\theta_{t+1} \ln \left(\frac{\theta_{t+1}}{\bar{\theta}}\right)+\left(1-\theta_{t+1}\right) \ln \left(\frac{1-\theta_{t+1}}{1-\bar{\theta}}\right)\right\} \\
& \simeq 1 / 2 * \operatorname{var}(\theta)\left[\frac{1}{\bar{\theta}}+\frac{1}{(1-\bar{\theta})}\right] .
\end{aligned}
$$

\footnotetext{
${ }^{14}$ See Cole and Obstfeld [1991].
} 
Proof. See the Appendix.

The gain to a monetary union comes from the ability of agents to respond to the realization of their taste shocks. Analytically, this gain is reflected in the $\operatorname{var}(\theta)$ term in $\Lambda_{S F}$ : increases in the variability of the taste shocks will reduce $V_{F}$ and thus increase $\Lambda_{S F}$. Further, the reduction in the number of stabilization tools in each country (due to the creation of a central monetary authority) does not limit the extent to which agents are insured against aggregate shocks. Essentially, the fiscal authorities can respond to country specific unemployment shocks and thus efficiently insure the incomes of agents against employment risk. The risk associated with unemployment variations is dissipated in the goods markets.

Relative to the planner's solution, the allocation under a strong central bank succeeds in producing optimal risk sharing. However, as in the case of multiple currencies, the labor supply decision is not first best. ${ }^{15}$

Overall, in contrast to the predictions arising from the work of Mundell, there is no trade-off between stabilization policy losses and reductions in transactions costs associated with the creation of a monetary union. Given that the fiscal authorities retain stabilization tools (income taxes), there are no stabilization losses associated with a monetary union. This conclusion does not require a high correlation of employment shocks. Essentially the existence of another instrument, fiscal policy, substitutes for monetary policy so that delegation of monetary control is not costly. Thus the emphasis on the correlation of shocks within the Mundellian framework is overstated. ${ }^{16}$

\section{Robustness}

We evaluate the robustness of our conclusions in two important directions. In both cases, our goal is to understand the conditions under which a monetary union is welfare improving relative to the monetary arrangement with multiple currencies.

First, we broaden our perspective on stabilization policy to consider an environment with fixed prices. Here we find that if price inflexibility is the only imperfection, then a version of Proposition 5 holds: the monetary union is welfare improving regardless of the correlation of shocks. But, if this imperfection is supplemented by a need for unemployment insurance, then a version of Proposition 3 holds. We conclude from this exercise that the source of the imperfection is not crucial for the Mundellian trade-off. Rather, it is whether existing (as well as potential) policy instruments are numerous and flexible enough to deal with existing market imperfections in the absence of country-specific monetary interventions.

Second, we consider a monetary union in which the central bank lacks commitment power vis-a-vis the national fiscal authorities. We term this a weak monetary union. We find that a monetary union may no longer be welfare improving even if each country

\footnotetext{
${ }^{15}$ The equilibrium employment level, $\bar{n}$, is not the solution to (21) unless $q$ equals 1 . If taxes were lump sum, then the efficient employment level could be supported.

${ }^{16}$ In other words, the development of alternative instruments (such as fiscal policy measures) is crucial for dealing with residual objectives once monetary policy is delegated, regardless of the correlation of shocks.
} 
maintains control over its fiscal policy. In effect, the creation of a weak monetary union provides each government with an opportunity to design an inflation tax on the other country which, in equilibrium, may lead to lower overall welfare. This leads us to emphasize that the completeness of the set of instruments is not enough to ensure that the Mundellian tradeoff disappears. Equally important are the relationships between the various policymakers involved in the stabilization game and, in particular, the commitment power of the monetary authority vis-à-vis the national fiscal authorities.

\section{A. Stabilization Policy with Predetermined Prices}

Thus far, we have emphasized a particular form of stabilization policy: risk-sharing between employed and unemployed agents. This focus reflects, in part, the importance of this form of cyclical intervention in many economies. Nonetheless, an alternative perspective on stabilization policy concerns the determination of total output and not its distribution. We outline a model based upon an assumption of predetermined prices that is closer in spirit to that view of stabilization: in the absence of stabilization policy, employment and output will be inefficient. ${ }^{17}$ Our main conclusion on the welfare gains from a strong monetary union remains. If fiscal policy is available as a stabilization device, there are no losses from the delegation of monetary policy to a single central bank.

We consider a version of our economy in which preferences are linear in consumption and $\theta \in\{0,1\}$ so that agents consume either the home or the foreign good. Let $\gamma$ be the probability that $\theta=1$. With this specification there are no gains to risk sharing either within or across countries. This allows us to focus on the role of stabilization policy with price rigidities. We return to more general specifications later.

The planner's solution once again provides a useful benchmark. The planner solves $\max _{n, n^{*}} q n+q^{*} n^{*}-q g(n)-q^{*} g\left(n^{*}\right)$. The first two terms are the consumption levels of the home and foreign goods by old agents. ${ }^{18}$ The second set of terms is the disutility of work for employed agents in the two countries. The solution is for employment to be a constant $\tilde{n}$ such that $g^{\prime}(\tilde{n})=1 .^{19}$

As for price rigidity, we assume that prices are predetermined at $\bar{p}$. We do not provide a rationale for this price rigidity: our interest is in its consequences. Given these prices, employment and hence output are determined by the level of nominal demand. With the added friction of price rigidity, there is a role for stabilization policy. Absent a monetary union, each government would use its monetary and/or fiscal policies to guarantee that the levels of employment and output were efficient. Interestingly, in contrast to the flexible price model, interventions work through their effects on aggregate demand and not through labor

\footnotetext{
${ }^{17}$ Several recent papers have attempted to introduce price rigidity in a model of a monetary union. See Benigno [2001], Devereux et al. [1999] and Leith and Wren-Lewis [2001].

${ }^{18}$ By symmetry, a fraction $\gamma$ of home agents consume the home good and a fraction $(1-\gamma)$ of the foreign agents also consume the home good.

${ }^{19}$ Alternatively, this can be seen from (21) where the $n q$ and $n^{*} q^{*}$ terms disappear when preferences over consumption are linear.
} 
supply.

To study stabilization within the monetary union, suppose that the single central bank keeps the nominal stock of money fixed. We allow each national government a simple fiscal policy: taxation of the nominal income of the young which is transferred to the old home agents who consume the home good. Thus if the domestic tax rate on nominal labor income is given by $\tau$, then the government collects nominal revenue of $T=\tau \bar{p} q n$. Total nominal spending on domestic goods is given by $M+T$ so that goods market clearing is

$$
\frac{M+T}{\bar{p}}=q n
$$

where $q$ is the fraction of workers with jobs, $n$ is the level of output (employment) per worker, $T$ is a nominal transfer made to old home agents who consume the home good and $M$ is the fraction of the aggregate money stock spent on the home market. ${ }^{20}$ Using the expression for total nominal tax revenues, this condition becomes

$$
\frac{M+\tau \bar{p} q n}{\bar{p}}=q n
$$

Clearly, if there is no fiscal intervention $(\tau=0)$ and the money supply is held constant, then in order for (36) to hold, $n$ must vary with $q$. Yet this response of employment to $q$ is inefficient since it differs from $\tilde{n}$.

Hence some form of intervention by the national fiscal authority is warranted. The home government solves

$$
\max _{\tau} \frac{\gamma M+\tau \bar{p} q n}{\bar{p}}-g(n) q
$$

where the dependence of $n$ on $\tau$ comes from (36). In this objective function, $\frac{\gamma M+\tau \bar{p} q n}{\bar{p}}$ is the consumption of old home agents. The first-order condition implies that $\tau$ be chosen so that $\left(g^{\prime}(n)=1\right)$, i.e., $n=\tilde{n}$.

Thus, even in the absence of active monetary policy by the single central bank, efficient stabilization policy can be undertaken using fiscal policy. Further, the liquidity benefits of a single currency outlined earlier remain. Hence a version of Proposition 5 holds: with fiscal policy appropriately chosen, there is a gain to a monetary union regardless of the correlation of shocks.

Using this result as a reference point, a trade-off may be created in two ways. Each of these variations illustrates the importance of the number of frictions relative to the policy instruments available to the national fiscal authorities and the central bank.

First, suppose there is no fiscal policy at the national level. ${ }^{21}$ Then a version of Proposition 3 will hold. If shocks are sufficiently correlated, then active policy by the single

\footnotetext{
${ }^{20}$ In the monetary union with symmetric countries, this is half of the fixed stock of currency.

${ }^{21}$ Cooper and Kempf [2000] provide an explicit example with fiscal policy that is, by assumption, not state contingent and reach the same conclusion.
} 
central bank, in the form of proportional transfers to the old agents in each country, will suffice to stabilize employment at its efficient level. Here the effect of monetary policy on employment comes directly from (35). However, if these shocks are not sufficiently correlated, then the delegation will be costly, and a monetary union may be welfare reducing.

Alternatively, suppose that we retain the national fiscal policy but amend the model to again include risk averse agents as in (1). This additional imperfection will also lead to a version of Proposition 3. If shocks are sufficiently correlated across countries, then monetary policy can be used to stabilize employment and fiscal policy can be used to provide unemployment insurance. But, when shocks are not sufficiently correlated, then the delegation of monetary policy to a single central bank will entail a stabilization loss.

\section{B. Weak Monetary Union}

From the previous analysis, we see the importance of a sufficiently rich set of policy instruments in order to achieve stabilization. However, the existence of the Mundellian tradeoff dilemma is not simply a matter of counting policy tools relative to imperfections. Both governments must have an incentive to use their policy tools in a manner consistent with the welfare of all agents involved in the union. Otherwise, they may be induced to act strategically so that a monetary union is not welfare improving. To illustrate this, we consider the following experiment.

We define a weak central bank by two institutional features: (i) the two national fiscal authorities move first but act non-cooperatively and (ii) the central monetary authority moves second and fully finances the total sum of national deficits of the two governments. While the only difference here compared to the strong central bank model is the timing of moves, this change has very strong economic implications: the central bank is obligated to monetize deficits. This weak central bank functions under a full bail-out clause in which it is committed to meeting the financial needs of the fiscal authorities of member governments.

There are a number of reasons for studying a weak monetary union. First, through this extreme institution, one can better understand the benefits of imposing a no-bail-out clause, as appears to be the case in the European Monetary Union. Second, to the extent that a central bank cannot commit to a no-bail-out clause, understanding the outcomes in this extreme case are of interest. ${ }^{22}$ Third, there are examples of countries in which independent authorities interacted through a common central bank, leading to excessive inflation. ${ }^{23}$ Finally, though our model has no interest bearing government debt, the weak monetary union case captures the implications of a monetary authority which monetizes the debt of fiscal authorities. ${ }^{24}$

\footnotetext{
${ }^{22}$ In fact, Beetsma and Uhlig [1999, p. 546] motivate their study of the "Stability Pact" by noting "there is fear that a high deficit member country or a member country in recession may successfully pressure the ECB into loosening its monetary policy."

${ }^{23}$ This is the basis for the Cooper and Kempf [2001] investigation of the potential gains to dollarization. There are other studies of the interaction between independent parts of a government that share a common budget constraint. See, for example, Aizenman [1992], Aizenman and Powell [1998], Zarazaga [undated] and Chari and Kehoe [1998] for discussions of this point in the context of macroeconomics.

${ }^{24}$ This issue of policy coordination arises in Sargent and Wallace [1981]. In the appendix of that paper, they
} 


\section{Equilibrium Analysis}

Because the interaction between the various policymakers is the only difference between this structure and the other forms of monetary union, (24)-(26) again characterize the consumption and labor supply decision rules of agents given monetary and fiscal policies. As before, each government provides unemployment insurance to agents currently unemployed. These flows are financed by tax revenues from employed agents and from the printing of money. Since the central bank is required to finance the deficits of the two governments, the evolution of the money supply is given by

$$
M_{t+1}=M_{t}+\left[\left(1-q_{t}\right) b_{t}^{W}-p_{t} n_{t} q_{t} \tau_{t}^{W}\right]+\left[\left(1-q_{t}^{*}\right) b_{t}^{* W}-p_{t}^{*} n_{t}^{*} q_{t}^{*} \tau_{t}^{*}\right]=M_{t}+\Delta_{t}^{W}+\Delta_{t}^{* W}
$$

where $\Delta_{t}^{W}\left(\Delta_{t}^{* W}\right)$ denote the monetary deficit, $b_{t}^{W}\left(b_{t}^{* W}\right)$ the transfer to the unemployed and $\tau_{t}^{W}\left(\tau_{t}^{* W}\right)$ the tax rate set in a "weak" environment in the home (foreign) country. Put differently, the change in the money supply equals the sum of the nominal deficits across the two countries.

As (38) makes clear, the weak monetary union introduces an interaction across the fiscal authorities that did not exist in either the multiple currency or strong monetary union cases. Specifically, under a weak monetary union, deficit spending by one country is financed by an inflation tax that is partially paid by the agents of the other country. Thus the "beggar thy neighbor" type seignorage policies that promoted gains to a monetary union in the multi-currency world economy of Cooper and Kempf [forthcoming] reappear here under a weak central bank. ${ }^{25}$

Taking the response of the weak monetary authority as given, each fiscal authority in period $t$ noncooperatively chooses the level of taxes and UI benefits to maximize the expected utility of generation $t$ agents. In doing so, each government fully perceives the effects of its policies on equilibrium prices.

In general, characterizing additional features of this equilibrium is difficult since the presence of country specific shocks implies that the distribution of the nominal money supply across the two countries is stochastic. Hence in the remainder of this section we make an additional assumption that the economies are symmetric: $\bar{\theta}=\frac{1}{2}$.

Let $D_{t}$ represent the level of nominal spending in period $t+1$ on the home good by generation $t$ (home and foreign) agents. $D_{t}$ is also the nominal income of generation $t+1$

outline an overlapping generations model with government debt, private storage and money as alternative assets. Through restricted participation in asset markets, they characterize an equilibrium in which the real rate of return exceeds the growth of the economy. The consequence of this for the case in which the monetary authority moves after the fiscal authority, in their words, is: "Sooner or later in a monetarist economy the result is additional inflation."

${ }^{25}$ Interestingly, these effects were absent in the other institutional settings. This is a consequence of our timing assumptions: agents were able to go to exchange markets after receiving government transfers. In contrast, Cooper and Kempf [forthcoming] assume that the transfers are received after the exchange markets are closed, thus providing a tax base for seignorage. 
employed agents. From market clearing,

$$
p_{t+1} q_{t+1} \bar{n}=D_{t}=\bar{\theta}\left(q_{t} I_{t}^{E}+\left(1-q_{t}\right) I_{t}^{U}\right)+(1-\bar{\theta})\left(q_{t}^{*} I_{t}^{* E}+\left(1-q_{t}^{*}\right) I_{t}^{* U}\right) .
$$

Using $\bar{\theta}=\frac{1}{2}$, the evolution of $D_{t}$ is given by

$$
D_{t}=\frac{1}{2}\left[D_{t-1}+D_{t-1}^{*}+\Delta_{t}^{W}+\Delta_{t}^{* W}\right]
$$

With this added structure we find

Proposition 6.. With $\bar{\theta}=\frac{1}{2}$, there is a symmetric equilibrium in which all income taxes are zero and $\Delta_{t}^{W}=2 \frac{\left(1-q_{t}\right)}{\left(q_{t}+q_{t}^{*}-1\right)} D_{t-1}, \Delta_{t}^{* W}=2 \frac{\left(1-q_{t}^{*}\right)}{\left(q_{t}+q_{t}^{*}-1\right)} D_{t-1}^{*}$ and $D_{t}=D_{t}^{*}$ for all $t$.

Proof. See the Appendix.

According to this proposition, when the central bank is weak, there is no direct taxation by either country to finance transfers to its unemployed people. To the contrary, all transfers are fully monetized. ${ }^{26}$ Financing unemployment compensation through this inflation tax is a dominant strategy for each of the governments since part of the tax burden is borne by agents outside their country. Nevertheless there is a limit to the amount raised through monetization since the higher prices lead to a reduction in the utility of young employed agents.

The equilibrium is symmetric: each country runs a deficit in each period which is proportional to the level of nominal spending in that country. The rates of money creation are dependent on the level of unemployment in each of the countries. Since the deficit spending is used to finance a transfer to unemployed agents which is partially paid for by the employed agents, it is natural that the rate of money creation will be an increasing function of the unemployment rate in the home country.

The equilibrium rate of money creation is given by

$$
\mu_{t}^{W}=\frac{2-q_{t}-q_{t}^{*}}{q_{t}+q_{t}^{*}-1}
$$

Clearly, money growth is zero if both economies exhibit full employment and is increasing in the rates of unemployment of member countries.

\section{Welfare Comparisons: Weak Monetary Union vs. Multiple Currencies}

A characteristic of a weak monetary union is that incomes of unemployed and employed agents are not equalized within a country. Hence, as they face the same prices, their consumption allocations will not be the same, for a given realization of the taste shock $\theta$. So, the allocation under a weak monetary union will not satisfy the conditions for optimal risk sharing: this institution does not facilitate stabilization through the available policy in-

\footnotetext{
${ }^{26}$ In some countries, such as Argentina, Brazil and Russia, there is vivid evidence of the inflation predicted by this proposition.
} 
struments. ${ }^{27}$ Instead, these fiscal policies are used strategically in order to induce the central monetary authority to create money. Still, the monetary union does eliminate consumption misallocations in the presence of taste shocks. Hence, a new trade-off emerges between these welfare gains and the losses resulting from the inflation game between the two governments.

Proposition 7.. If the variability of the taste shock is sufficiently small and $\bar{q}$ and $\bar{q}^{*}$ are sufficiently below 1 , then $V_{W}<V_{F}$. If $\bar{q}$ and $\bar{q}^{*}$ are near 1 and the variability of taste shocks is large enough, then $V_{W}>V_{F}$.

Proof. See the Appendix.

For the weak central bank, Proposition 6 indicates the dependence of each country's deficit on its rate of unemployment. If unemployment rates are sufficiently low on average, then a monetary union will not create excessive inflation. In that case, Proposition 7 implies that even a monetary union with a weak central bank can be welfare improving.

\section{Conclusion}

The goal of this paper has been to examine the welfare consequences of a monetary union, with particular emphasis on the supposed trade-off between efficient gains from eliminating multiple currencies and the welfare losses from the delegation of monetary policy, emphasized by Mundell. To do so, we explored the allocations of a stochastic two-country overlapping generations model under alternative monetary/fiscal institutions. In this way, we are able to characterize the response of individual behavior and welfare to variations in international monetary arrangements.

In the extreme case of a strong central monetary authority with commitment power and fiscal authorities with the ability to set state contingent tax rates, a monetary union unambiguously increases welfare. In this institutional design, the delegation of monetary policy to a single central bank does not jeopardize the conduct of stabilization policy. The trade-off envisioned by Mundell and others does not exist. Further, the gain to a monetary union does not rest on labor mobility since in our model labor is immobile.

However, there are designs of a monetary union which do not increase welfare precisely because stabilization policy is impaired. In particular, if the set of policy instruments open to fiscal authorities is sufficiently restricted, then the monetary union may not increase welfare. This is seen by comparing Propositions 3 and 5 and is important in the addition of price inflexibility into our model. ${ }^{28}$ Despite having commitment power, the central bank lacks the tools to stabilize in the presence of country specific shocks that are not perfectly correlated. This result is consistent with the Mundellian trade-off.

Further, if the monetary authority is weak and thus influenced by the deficit spending

\footnotetext{
${ }^{27} \mathrm{So}$, as shown in Cooper and Kempf [2000], the resulting allocation provides lower welfare than that achieved by a monetary union with a strong central bank.

${ }^{28}$ Cooper-Kempf [2000] also study a case in which fiscal policy is not state contingent and obtain similar results.
} 
of member countries, then the gains to a monetary union may be more than offset by the adverse consequences of inflation. A weak central bank allows strategic interaction by the fiscal authorities and thus excessive inflation.

These results are normative in that they point to potential gains from a monetary union. Will these gains be realized? Cooper-Kempf [forthcoming] argue that though there are gains to a monetary union, the incentives for each country imply that these welfare gains will not be realized without collective action. In particular, a game in which countries, in effect, decide to join a monetary union or not has a prisoners' dilemma structure: the cooperative outcome of a monetary union is not a Nash equilibrium of this game. Those results can be extended to the environment studied here.

In terms of further analysis, a number of important extensions come to mind. First, our analysis of stabilization policy looks exclusively at supply shocks. This is relevant since these shocks produce price movements which tend to stabilize nominal incomes. As noted earlier, this feature of markets created an element of stability even with a non-interventionist monetary authority. Clearly, extending the analysis to a setting with demand side shocks (including financial crises) and thus no countervailing price movements is of interest.

Second, the issue of stabilization policy in a monetary union could be further pursued by analyzing the consequences of fiscal federalism. Such an institutional arrangement adds new fiscal instruments by facilitating transfers across countries and may be useful for stabilization when other sources of fluctuations are present. ${ }^{29}$ As with the delegation of monetary policy, a system of fiscal federalism may create stabilization losses, though the gains of policy coordination may offset them.

Third, the model we have studied does not include interest bearing public debt issued by individual nations. Introducing national debt into the model would bring it closer to observations, including the current discussion of restrictions on the size of deficits in the EMU as well as the issuance of small denominated bonds by provincial governments in Argentina. Further, this extension would allow us to evaluate alternative monetary rules. In particular, one might conjecture that certain monetary rules, such as interest rate targets, place the central bank at a strategic disadvantage (as in the weak monetary union case) relative to national governments.

Finally, there is the open question of how to quantitatively assess the stabilization losses from the delegation of monetary policy in a monetary union. Following Mundell,

\footnotetext{
${ }^{29}$ Cooper and Kempf [2000] provide an example in which home and foreign goods are perfect substitutes in agents' utility functions. Without central bank intervention, nominal GDP in the home country will not equal nominal GDP in the foreign country unless employment shocks are perfectly positively correlated. Hence, risk sharing across countries will be imperfect in the absence of central bank intervention. In fact, the central bank should create money and transfer it to the fiscal authority of the government in the country with the low level of nominal GDP. Given these funds, the fiscal authorities will equalize the nominal incomes of employed and unemployed agents. In effect, the optimal central bank rule is to stabilize nominal GDP and not necessarily prices. In equilibrium, this equalization of nominal incomes will lead to efficient allocations of risk both within and across countries. One might want to interpret these transfers as a form of fiscal federalism.
} 
several studies have attempted to evaluate the amount of shock asymmetry in Europe so as to know whether Europe is an "optimal currency area." 30 From our analysis, this approach is misguided because it ignores the existence of other tools for stabilization. In the extreme case studied in our paper, fiscal policy could perfectly substitute for monetary policy so that there were no costs to delegation for any pattern of correlations. Our analysis suggests, in theory, an alternative measure of stabilization losses from the creation of a monetary union. Consider a multiple currency environment with an inactive central bank. Design optimal fiscal policies in each country. Then introduce country specific monetary policy to deal with any remaining distortions. If these country specific monetary policies are highly correlated, then delegation of monetary policy to a single central bank will not be very costly. Thus the key correlation is not in the shocks per se but in the monetary policy that is used to respond to these shocks given optimally designed fiscal policy.

\footnotetext{
${ }^{30}$ See, as good examples of these exercises, Bayoumi and Eichengreen [1994] and Helg et al. [1995].
} 


\section{References}

Aizenman, J., "Competitive Externality and Optimal Seigniorage," Journal of Money, Credit and Banking, 24 (1992), 61-71.

Aizenman, J. and A. Powell, "The Political Economy of Public Savings and the Role of Capital Mobility," Journal of Development Economics, 57(1998), 67-95.

Alvarez, F., A. Atkeson and P. Kehoe, "Money, Interest Rates and Exchange Rates with Endogenously Segmented Asset Markets," NBER WP \#7871, September 2000.

Bayoumi, T. and B. Eichengreen, "One Money or Many? Analyzing the Prospects for Monetary Unification in Various Parts of the World," Princeton Studies in International Finance, \# 76, 1994.

Beetsma, R. and H. Uhlig, "An Analysis for the Stability and Growth Pact," Economic Journal, 109 (1999), 546-571.

Benigno P., "Optimal Monetary Policy in a Currency Area," CEPR Discussion Paper \# 2755, April 2001.

Buiter, W., "The EMU and the NAMU: What is the Case for North-American Monetary Union?" CEPR Discussion Paper \# 2181, June 1999.

Chari, V. V. and P. Kehoe, "On the Need for Fiscal Constraints in a Monetary Union," Federal Reserve Bank of Minneapolis, Working Paper \#589, August 1998.

Chatterjee, S. and D. Corbae, "Endogenous Market Participation and the General Equilibrium Value of Money," Journal of Political Economy, 100 (1992), 615-642.

Christiano, L. and M. Eichenbaum, "Liquidity Effects and the Monetary Transmission Mechanism," American Economic Review, 82 (1992), 344-353.

Cole, H. L. and M. Obstfeld, "Commodity Trade and International Risk Sharing: How much Do Financial Markets Matter?" Journal of Monetary Economics, 28(1991), 3-24.

Cooper, R. and H. Kempf, "Commitment and the Adoption of a Common Currency," International Economic Review, forthcoming.

Cooper, R. and H. Kempf, "Designing Stabilization Policy in a Monetary Union," NBER Working Paper \#7607, March 2000.

Cooper, R. and H. Kempf, "Dollarization and the conquest of hyperinflation in divided societies," Federal Reserve Bank of Minneapolis Quarterly Review, 25 (3), Summer 2001.

Devereux, M., C. Engel and C. Tille, "Exchange-rate Pass-Through and the Welfare Effects of the Euro," NBER Working Paper \# 7382, October 1999.

Emerson, M., D. Gros, A. Italianer, J. Pisany-Ferry and J. Reichenbach, One Market, One Money, Oxford University Press, 1992.

Feldstein, M., "The Political Economy of the European Economic and Monetary Union: Political Sources of an Economic Liability," Journal of Economic Perspectives, 11 (1997), 23-42.

Fuerst, T., "Liquidity, Loanable Funds and Real Activity," Journal of Monetary Economics, 29(1992), 3-24. 
Helg, R., P. Manasse, T. Monacelli and R. Rovelli, "How much (A)symmetry in Europe? Evidence from Industrial Sectors," European Economic Review, 39(1995), 1017-1047.

Leith, C. and S. Wren-Lewis, "Interactions Between Monetary and Fiscal Policy under EMU," mimeo, paper presented at the conference, The Macroeconomics of EMU, Milan, September 2001.

Lucas, R. E. Jr., "Liquidity and Interest Rates," Journal of Economic Theory, 50 (1990), 237-264.

Mundell, R., "A Theory of Optimum Currency Areas," American Economic Review, 51 (1961), 657-665.

Sargent, T. and N. Wallace, "Some Unpleasant Monetarist Arithmetic," Federal Reserve of Minneapolis Quarterly Review, 5 (1981), 1-17.

Zarazaga, C., "Recurrent Hyperinflations in a Dynamic Game with Imperfect Monitoring in the Appropriation of Seignorage," Federal Reserve Bank of Dallas, undated. 


\section{APPENDIX}

Proposition 1.. In a world economy with multiple currencies, given government unemployment benefits, home consumption allocations are given by

$$
\begin{aligned}
c_{t+1}^{E h} & =\bar{\theta} \cdot \frac{q_{t+1}}{q_{t}} \cdot \frac{1}{1+\mu_{t}^{F}} \cdot \bar{n}, \quad c_{t+1}^{E f}=(1-\bar{\theta}) \cdot \frac{q_{t+1}^{*}}{q_{t}} \cdot \frac{1}{1+\mu_{t}^{F}} \cdot \bar{n} \\
c_{t+1}^{U h} & =\bar{\theta} \cdot \frac{q_{t+1}}{1-q_{t}}\left(\frac{\mu_{t}^{F}}{1+\mu_{t}^{F}}\right) \bar{n}, \quad c_{t+1}^{U f}=(1-\bar{\theta}) \cdot \frac{q_{t+1}^{*}}{1-q_{t}}\left(\frac{\mu_{t}^{F}}{1+\mu_{t}^{F}}\right) \bar{n} .
\end{aligned}
$$

Proof. The proof proceeds by characterizing the consumption levels of home and foreign goods by home employed and unemployed agents. Analogous expressions are derived for the consumption levels of foreign agents.

A. Home Consumption by a home employed agent

The maximization problem solved by an employed, generation $t$ home agent is

$$
\begin{aligned}
\max _{n_{t}, m_{t}^{E h}, m_{t}^{E f}} E_{\theta}\left\{\theta_{t+1} \ln \left(c_{t+1}^{E h}\right)+\left(1-\theta_{t+1}\right) \ln \left(c_{t+1}^{E f}\right)\right\}-g\left(n_{t}\right) \\
\text { s.t. } \quad p_{t} n_{t}=m_{t}^{E h}+e_{t} m_{t}^{E f} \\
p_{t+1} c_{t+1}^{E h}=m_{t}^{E h} \quad p_{t+1}^{*} c_{t+1}^{E f}=m_{t}^{E f}
\end{aligned}
$$

Substituting for $m_{t}^{E f}$, optimizing over $n_{t}$ and $m_{t}^{E h}$ yields two first-order conditions:

$$
\begin{aligned}
g^{\prime}\left(n_{t}\right) & =\frac{p_{t}(1-\bar{\theta})}{p_{t} n_{t}-m_{t}^{E h}} \\
\frac{\bar{\theta}}{1-\bar{\theta}} & =\frac{m_{t}^{E h}}{p_{t} n_{t}-m_{t}^{E h}} .
\end{aligned}
$$

Equation (48) implies $m_{t}^{E h}=\bar{\theta} p_{t} n_{t}$. From this and (45), $e_{t} m_{t}^{E f}=(1-\bar{\theta}) p_{t} n_{t}$. Substitution of these money demands into (46) yields the expressions for consumption in (6).

Let $\phi_{t}^{E}$ be the fraction of the home money stock held by employed young home agents: $\phi_{t}^{E} \equiv \frac{q_{t} m_{t}^{E h}}{M_{t}}$. This represents money holdings after the exchange markets open in period $t$. We exhibit an equilibrium in which $\phi_{t}^{E}$ is constant and equals $\phi^{E}$ for all $t$.

The condition for home currency money market equilibrium, $M_{t}=p_{t} n_{t} q_{t}$, along with (48) yield

$$
\frac{\bar{\theta}}{1-\bar{\theta}}=\frac{\phi_{t}^{E} M_{t} / q_{t}}{M_{t} / q_{t}\left(1-\phi_{t}^{E}\right)}
$$

so that $\phi_{t}^{E}=\phi^{E}=\bar{\theta}$. 
Multiplying both sides of (47) by $n_{t}$ and using money market clearing implies

$$
g^{\prime}\left(n_{t}\right) n_{t}=\frac{(1-\bar{\theta}) p_{t} n_{t}}{p_{t} n_{t}-m_{t}^{E h}}=\frac{(1-\bar{\theta}) M_{t} / q_{t}}{\left(1-\phi^{E}\right) M_{t} / q_{t}}=1
$$

because $\phi^{E}=\bar{\theta}$. This implies that the level of employment is constant at $\bar{n}$ where $g^{\prime}(\bar{n}) \bar{n}=1$.

To solve for $c_{t+1}^{E h}$, use the cash-in-advance constraint for home goods, (46), the money market clearing condition for all $t$ and the evolution of the home money supply $\left(M_{t+1}=\right.$ $\left.\left(1+\mu_{t}^{F}\right) M_{t}\right)$ to obtain

$$
c_{t+1}^{E h}=\frac{m_{t}^{E h}}{p_{t+1}}=\frac{\phi^{E} M_{t} / q_{t}}{M_{t+1} / q_{t+1} n_{t+1}}=\frac{\bar{\theta} q_{t+1} \bar{n}}{\left(1+\mu_{t}^{F}\right) q_{t}}
$$

as in the proposition.

There is an analogous optimization problem for a foreign employed agent. For that agent, $n_{t}^{*}=\bar{n}$ for all $t$. Further, consumption of the foreign good by the foreign employed agent is given by

$$
c_{t+1}^{* E f}=\frac{\bar{\theta} q_{t+1}^{*} \bar{n}}{\left(1+\mu_{t}^{* F}\right) q_{t}^{*}} .
$$

B. Home consumption by a home unemployed agent

The argument parallels that of the home employed agent. The maximization problem solved by an unemployed, generation $t$, home agent is

$$
\begin{aligned}
& \max _{m_{t}^{U h}, m_{t}^{U f}} E_{\theta}\left\{\theta_{t+1} \ln \left(c_{t+1}^{U h}\right)+\left(1-\theta_{t+1}\right) \ln \left(c_{t+1}^{U f}\right)\right\} \\
& \text { s.t. } \quad I_{t}^{U}=m_{t}^{U h}+e_{t} m_{t}^{U f} \\
& p_{t+1} c_{t+1}^{U h}=m_{t}^{U h} \quad p_{t+1}^{*} c_{t+1}^{U f}=m_{t}^{U f} .
\end{aligned}
$$

The first-order conditions lead to

$$
\frac{\bar{\theta}}{1-\bar{\theta}}=\frac{m_{t}^{U h}}{I_{t}^{U}-m_{t}^{U h}}
$$

Using (54) and (55), this condition implies

$$
c_{t+1}^{U h}=\frac{\bar{\theta} I_{t}^{U}}{p_{t+1}} .
$$

From the definition of the income for unemployed agents, $I_{t}^{U}=b_{t}^{F}=\frac{M_{t} \mu_{t}^{F}}{1-q_{t}}$, and money market clearing, home consumption by these agents is

$$
c_{t+1}^{U h}=\bar{\theta} \frac{q_{t+1}}{1-q_{t}}\left(\frac{\mu_{t}^{F}}{1+\mu_{t}^{F}}\right) \bar{n}
$$


as in the proposition. To derive this expression, we again used the market clearing condition for all $t$ and the evolution of the home money supply, $M_{t+1}=\left(1+\mu_{t}^{F}\right) M_{t}$.

As was the case for the employed agents in the two countries, there is an analogous optimization problem for the foreign unemployed agent. From that optimization problem,

$$
c_{t+1}^{* U f}=\bar{\theta} \bar{n} \frac{q_{t+1}^{*}}{1-q_{t}^{*}}\left(\frac{\mu_{t}^{* F}}{1+\mu_{t}^{* F}}\right) .
$$

C. Consumption of foreign goods by home agents

To characterize the consumption of foreign goods by home agents, we use the conditions for goods market clearing:

$$
\begin{aligned}
& q_{t+1} \bar{n}=q_{t} c_{t+1}^{E h}+\left(1-q_{t}\right) c_{t+1}^{U h}+q_{t}^{*} c_{t+1}^{* E h}+\left(1-q_{t}^{*}\right) c_{t+1}^{* U h} \\
& q_{t+1}^{*} \bar{n}=q_{t}^{*} c_{t+1}^{* E f}+\left(1-q_{t}^{*}\right) c_{t+1}^{* U f}+q_{t} c_{t+1}^{E f}+\left(1-q_{t}\right) c_{t+1}^{U f} .
\end{aligned}
$$

From (52) and (57),

$$
\frac{c_{t+1}^{* E f}}{c_{t+1}^{* U f}}=\frac{1-q_{t}^{*}}{\mu_{t}^{* F} q_{t}^{*}} .
$$

By symmetry,

$$
\frac{c_{t+1}^{E f}}{c_{t+1}^{U f}}=\frac{1-q_{t}}{\mu_{t}^{F} q_{t}} .{ }^{31}
$$

Substituting these conditions into (59) implies

$$
q_{t+1}^{*} \bar{n}=q_{t}^{*}\left(1+\mu_{t}^{* F}\right) c_{t+1}^{* E f}+q_{t}\left(1+\mu_{t}^{F}\right) c_{t+1}^{E f}
$$

Using (52) to substitute for $c_{t+1}^{* E f}$ yields

$$
c_{t+1}^{E f}=(1-\bar{\theta}) \cdot \frac{q_{t+1}^{*}}{q_{t}} \cdot \frac{1}{1+\mu_{t}^{F}} \cdot \bar{n}
$$

as in the proposition. Using (61),

$$
c_{t+1}^{U f}=(1-\bar{\theta}) \cdot \frac{q_{t+1}^{*}}{1-q_{t}}\left(\frac{\mu_{t}^{F}}{1+\mu_{t}^{F}}\right) \bar{n}
$$

as in the proposition.

Proposition 2.. In a world economy with flexible exchange rates and multiple currencies, the equilibrium money creation rates satisfy

$$
\frac{1}{1+\mu_{t}^{F}}=q_{t}, \frac{1}{1+\mu_{t}^{* F}}=q_{t}^{*}
$$

\footnotetext{
${ }^{31}$ This can also be shown directly from the ratio of foreign money holdings of the employed and unemployed home agents.
} 
Proof. Given $\mu_{t}^{* F}$ and the realized values of $\left(q_{t}, q_{t}^{*}\right)$, the home government solves

$$
\max _{\mu_{t}^{F}} E_{\left(\theta, q_{t+1}, q_{t+1}^{*}\right)}\left[q_{t} U\left(c_{t+1}^{E h}, c_{t+1}^{E f}, \bar{n}, \theta_{t+1}\right)+\left(1-q_{t}\right) U\left(c_{t+1}^{U h}, c_{t+1}^{U f}, 0, \theta_{t+1}\right)\right]
$$

where the consumption levels are from Proposition 1 and $\bar{n}$ solves (7). The first-order condition generates the equality in the proposition:

$$
\frac{1}{1+\mu_{t}^{F}}=q_{t}
$$

Proposition 3.. In a Mundellian monetary union, (i) if shocks are sufficiently correlated across countries and tastes are sufficiently variable, then the monetary union allocation will yield higher expected utility than the outcome with multiple currencies and (ii) if employment shocks are not perfectly positively correlated and taste shocks are not sufficiently variable, then the monetary union will not be welfare improving.

Proof. The single central bank maximizes the sum of lifetime expected utilities of all agents. Using (24), (25) and (26) and the analogous expressions for the foreign agents, the single central bank's optimization problem reduces to

$$
\begin{gathered}
\max _{\Delta_{t}^{M}} E\left\{q_{t} \ln \left(I_{t}^{E}\right)+\left(1-q_{t}\right) \ln \left(I_{t}^{U}\right)+q_{t}^{*} \ln \left(I_{t}^{* E}\right)+\left(1-q_{t}^{*}\right) \ln \left(I_{t}^{* U}\right)-\ln \left(p_{t+1}\right)-\ln \left(p_{t+1}^{*}\right)\right\}(67) \\
\text { s.t. } \quad \begin{array}{rll}
I_{t}^{E} & =p_{t} \bar{n} & I_{t}^{U}\left(1-q_{t}\right)=\Delta_{t}^{M} \\
I_{t}^{* E} & =p_{t}^{*} \bar{n} & I_{t}^{* U}\left(1-q_{t}^{*}\right)=\Delta_{t}^{M} .
\end{array}
\end{gathered}
$$

The first-order condition is

$$
\frac{\left(1-q_{t}\right)+\left(1-q_{t}^{*}\right)}{\Delta_{t}^{M}}-\frac{d p_{t+1}}{d \Delta_{t}^{M}} \frac{1}{p_{t+1}}-\frac{d p_{t+1}^{*}}{d \Delta_{t}^{M}} \frac{1}{p_{t+1}^{*}}=0 .
$$

From the market-clearing condition in the home goods market,

$$
p_{t+1} q_{t+1} \bar{n}=\left\{q_{t} \bar{\theta} I_{t}^{E}+q_{t}^{*}(1-\bar{\theta}) I_{t}^{* E}+\Delta_{t}^{M}\right\}
$$

There is an analogous expression for market clearing in the foreign goods market. Hence

$$
\frac{d p_{t+1}}{d \Delta_{t}^{M}}=\frac{1}{q_{t+1} \bar{n}} \quad \text { and } \quad \frac{d p_{t+1}^{*}}{d \Delta_{t}^{M}}=\frac{1}{q_{t+1}^{*} \bar{n}} .
$$


Then, (69) becomes

$$
\frac{\left(1-q_{t}\right)+\left(1-q_{t}^{*}\right)}{\Delta_{t}^{M}}=\frac{1}{p_{t+1} q_{t+1} \bar{n}}+\frac{1}{p_{t+1}^{*} q_{t+1}^{*} \bar{n}} .
$$

(i) Suppose that $\operatorname{corr}\left(q, q^{*}\right)$ is exactly 1. Then the two countries are perfectly symmetric ex post so that $p_{t}=p_{t}^{*}$ for all realizations of $\left(q_{t}, q_{t}^{*}\right)$. Hence nominal GDP is equal across countries: $p_{t+1} q_{t+1} \bar{n}=p_{t+1}^{*} q_{t+1}^{*} \bar{n}$. Using (70), market clearing and $M_{t+1}=M_{t}+2 \Delta_{t}^{M}$, the optimal central bank policy is to set $\Delta_{t}^{M}$ so

$$
I_{t}^{U}=I_{t}^{U *}=p_{t} \bar{n}=p_{t}^{*} \bar{n}
$$

This policy provides complete insurance to unemployed agents because their nominal income will equal that of an employed agent. Further, consumption optimally responds to variations in $\theta$. So, expected utility in a Mundellian monetary union with complete insurance is given by

$$
\begin{aligned}
V_{M}= & E\left\{\theta_{t+1} \ln \left(\theta_{t+1}\right)+\left(1-\theta_{t+1}\right) \ln \left(1-\theta_{t+1}\right)\right\} \\
& +E \ln \left(q_{t+1}\right)+\ln (\bar{n})-\bar{q} g(\bar{n}) .
\end{aligned}
$$

The difference between $V_{M}$ and $V_{F}$ is given by

$$
V_{M}-V_{F}=E\left\{\theta_{t+1} \ln \left(\frac{\theta_{t+1}}{\bar{\theta}}\right)+\left(1-\theta_{t+1}\right) \ln \left(\frac{1-\theta_{t+1}}{1-\bar{\theta}}\right)\right\}
$$

which, by a Taylor series expansion, is approximately

$$
\operatorname{var}(\theta)\left[\frac{1}{\bar{\theta}}+\frac{1}{(1-\bar{\theta})}\right]
$$

When $\operatorname{var}(\theta)$ is strictly positive, $V_{M}-V_{F}$ is strictly positive. Thus in the Mundellian monetary union with $\operatorname{corr}\left(q, q^{*}\right)=1$, welfare strictly exceeds $V_{F}$ when there are taste shocks. By continuity, this is true for $\operatorname{corr}\left(q, q^{*}\right)$ near 1.

(ii) If the variance of $\theta$ is zero and the $\operatorname{corr}\left(q, q^{*}\right)$ is exactly 1 , then there is no net gain to a Mundellian monetary union: there are zero transactions gains and no stabilization losses: $(73)=0$. For $\operatorname{corr}\left(q, q^{*}\right)$ less than 1 , there will be stabilization losses from the delegation of monetary policy to the central bank. From (68), if $q \neq q^{*}$, then it is impossible to find $\Delta_{t}^{M}$ such that $I_{t}^{E}=I_{t}^{U}$ and $I_{t}^{* E}=I_{t}^{* U}$. In this case, the Mundellian monetary union is not welfare improving. By continuity, this is true if the variance of $\theta$ is sufficiently low.

Proposition 4.. There exists an equilibrium in the strong monetary union where the rate of money creation is zero, irrespective of the values of the shocks, and the taxation rates are 
equal to

$$
\tau_{t}^{S}=1-q_{t} \quad \tau_{t}^{* S}=1-q_{t}^{*}
$$

The consumption allocations are given by

$$
\begin{gathered}
c_{t+1}^{E h}=c_{t+1}^{U h}=\theta_{t+1} q_{t+1} \bar{n} \quad \text { and } \quad c_{t+1}^{E f}=c_{t+1}^{U f}=\left(1-\theta_{t+1}\right) q_{t+1}^{*} \bar{n} \\
c_{t+1}^{* E h}=c_{t+1}^{* U h}=\left(1-\theta_{t+1}^{*}\right) q_{t+1} \bar{n} \quad \text { and } \quad c_{t+1}^{* E f}=c_{t+1}^{* U f}=\theta_{t+1}^{*} q_{t+1}^{*} \bar{n} .
\end{gathered}
$$

Employment allocations satisfy $n=n^{*}=\bar{n}$ where

$$
g^{\prime}(\bar{n}) \bar{n}=1
$$

Proof. Each government takes the transfer received by its unemployed agent from the central monetary authority, $\Delta_{t}^{S}$, as given. The first order conditions from the agents' maximization implies an optimization problem for the home government of

$$
\begin{gathered}
\max _{\tau_{t}^{S}} E\left\{q_{t} \ln \left(I_{t}^{E}\right)+\left(1-q_{t}\right) \ln \left(I_{t}^{U}\right)-\bar{\theta} \ln \left(p_{t+1}\right)-(1-\bar{\theta}) \ln \left(p_{t+1}^{*}\right)\right\} \\
\text { s.t. } \quad I_{t}^{E}=p_{t} \bar{n}\left(1-\tau_{t}^{S}\right) \quad I_{t}^{U}=p_{t} \bar{n} \tau_{t}^{S} \frac{q_{t}}{1-q_{t}}+\frac{\Delta_{t}^{S}}{1-q_{t}} .
\end{gathered}
$$

The first-order condition for the home government implies $I_{t}^{E}=I_{t}^{U}$. Using this condition, the home and foreign tax rates are given by

$$
\tau_{t}^{S}=\left(1-q_{t}\right)-q_{t} \frac{\Delta_{t}^{S}}{p_{t} q_{t} \bar{n}} \quad \tau_{t}^{* S}=\left(1-q_{t}^{*}\right)-q_{t}^{*} \frac{\Delta_{t}^{* S}}{p_{t}^{*} q_{t}^{*} \bar{n}} .
$$

Given this dependence of taxes on money transfers, the central monetary authority solves

$$
\begin{aligned}
\max E\left\{q_{t} \ln \left(I_{t}^{E}\right)+\left(1-q_{t}\right) \ln \left(I_{t}^{U}\right)+q_{t}^{*} \ln \left(I_{t}^{* E}\right)+\left(1-q_{t}^{*}\right) \ln \left(I_{t}^{* U}\right)\right. \\
\left.-\ln \left(p_{t+1}\right)-\ln \left(p_{t+1}^{*}\right)\right\} \\
\text { s.t. } \quad I_{t}^{E}=p_{t} \bar{n}\left(1-\tau_{t}^{S}\right) \quad I_{t}^{U}=p_{t} \bar{n} \tau_{t}^{S} \frac{q_{t}}{1-q_{t}}+\Delta_{t}^{S} \\
I_{t}^{* E}=p_{t}^{*} \bar{n}\left(1-\tau_{t}^{* S}\right) \quad I_{t}^{* U}=p_{t}^{*} \bar{n} \tau_{t}^{* S} \frac{q_{t}^{*}}{1-q_{t}^{*}}+\Delta_{t}^{* S} \\
\tau_{t}^{S}=\left(1-q_{t}\right)-q_{t} \frac{\Delta_{t}^{S}}{p_{t} q_{t} \bar{n}} \quad \tau_{t}^{* S}=\left(1-q_{t}^{*}\right)-q_{t}^{*} \frac{\Delta_{t}^{* S}}{p_{t}^{*} q_{t}^{*} \bar{n}} .
\end{aligned}
$$

The first-order conditions are

$$
\frac{1}{I_{t}^{U}}-\frac{d p_{t+1}}{d \Delta_{t}^{S}} \frac{1}{p_{t}}-\frac{d p_{t+1}^{*}}{d \Delta_{t}^{S}} \frac{1}{p_{t}^{*}}=0 \quad \frac{1}{I_{t}^{* U}}-\frac{d p_{t+1}^{*}}{d \Delta_{t}^{* S}} \frac{1}{p_{t}^{*}}-\frac{d p_{t+1}}{d \Delta_{t}^{* S}} \frac{1}{p_{t}}=0 .
$$


From market-clearing conditions, we find

$$
p_{t+1} q_{t+1} \bar{n}=\left\{q_{t} \bar{\theta} I_{t}^{E}+\left(1-q_{t}\right) \bar{\theta} I_{t}^{U}+q_{t}^{*}(1-\bar{\theta}) I_{t}^{* E}+\left(1-q_{t}^{*}\right)(1-\bar{\theta}) I_{t}^{* U}\right\}
$$

Hence

$$
\frac{d p_{t+1}}{d \Delta_{t}^{S}}=\frac{\bar{\theta}}{q_{t+1} \bar{n}} \quad \text { and } \quad \frac{d p_{t+1}}{d \Delta_{t}^{* S}}=\frac{1-\bar{\theta}}{q_{t+1} \bar{n}}
$$

and similarly

$$
\frac{d p_{t+1}^{*}}{d \Delta_{t}^{S}}=\frac{1-\bar{\theta}}{q_{t+1}^{*} \bar{n}} \quad \text { and } \quad \frac{d p_{t+1}^{*}}{d \Delta_{t}^{* S}}=\frac{\bar{\theta}}{q_{t+1}^{*} \bar{n}} .
$$

Then, taking the values for the tax ratios into consideration, the first-order conditions of the central bank become

$$
\begin{gathered}
\frac{1}{p_{t} \bar{n} q_{t}+\Delta_{t}^{S}}-\frac{\bar{\theta}}{q_{t+1} \bar{n} p_{t}}-\frac{1-\bar{\theta}}{q_{t+1}^{*} \bar{n} p_{t}^{*}}=0, \\
\frac{1}{p_{t}^{*} \bar{n} q_{t}^{*}+\Delta_{t}^{* S}}-\frac{\bar{\theta}}{q_{t+1}^{*} \bar{n} p_{t}^{*}}-\frac{1-\bar{\theta}}{q_{t+1} \bar{n} p_{t}}=0 .
\end{gathered}
$$

We guess $\Delta_{t}^{S}=\Delta_{t}^{* S}=0$ is a solution and show it is consistent with the first-order conditions. If $\Delta_{t}^{S}=\Delta_{t}^{* S}=0$, we have seen that the solution of (78) subject to (79) implies that the individual governments will equate incomes irrespective of employment status. With $\Delta_{t}^{S}=\Delta_{t}^{* S}=0$, this equality of incomes requires

$$
\tau_{t}^{S}=\left(1-q_{t}\right) \quad \tau_{t}^{* S}=\left(1-q_{t}^{*}\right)
$$

The consumption and employment allocations for home agents are then obtained by evaluating (24), (25) and (26) given these policy choices. Similar expressions hold for foreign agents.

Proposition 5.. The difference in expected utilities achieved in a strong monetary union and a flexible exchange rate world economy with multiple currencies is always positive and equals

$$
\begin{aligned}
\Lambda_{S F} & \equiv V_{S}-V_{F}=E\left\{\theta_{t+1} \ln \left(\frac{\theta_{t+1}}{\bar{\theta}}\right)+\left(1-\theta_{t+1}\right) \ln \left(\frac{1-\theta_{t+1}}{1-\bar{\theta}}\right)\right\} \\
& \simeq 1 / 2 * \operatorname{var}(\theta)\left[\frac{1}{\bar{\theta}}+\frac{1}{(1-\bar{\theta})}\right] .
\end{aligned}
$$

Proof. This expression for $\Lambda_{S F}$ comes directly from the difference between (20) and (33). Taking the second-order Taylor approximation of this expression, this gain associated to a strong monetary union is

$$
\Lambda_{S F}=\frac{1}{2} * \operatorname{var}(\theta)\left[\frac{1}{\bar{\theta}}+\frac{1}{(1-\bar{\theta})}\right]
$$


$\Lambda_{S F}>0$ if $\operatorname{var}(\theta)>0$ because $\bar{\theta} \in(0,1)$.

Proposition 6.. With $\bar{\theta}=\frac{1}{2}$, there is a symmetric equilibrium in which all income taxes are zero and $\Delta_{t}^{W}=2 \frac{\left(1-q_{t}\right)}{\left(q_{t}+q_{t}^{*}-1\right)} D_{t-1}, \Delta_{t}^{* W}=2 \frac{\left(1-q_{t}^{*}\right)}{\left(q_{t}+q_{t}^{*}-1\right)} D_{t-1}^{*}$ and $D_{t}=D_{t}^{*}$ for all $t$.

Given the expressions for consumption levels and using the fact that $n_{t}=\bar{n}$, the maximization problem of the home government can be rewritten as

$$
\begin{gathered}
\max _{\tau_{t}^{W}, \Delta_{t}^{W}}\left\{q_{t} \ln I_{t}^{E}+\left(1-q_{t}\right) \ln I_{t}^{U}-\bar{\theta} \ln p_{t+1}-(1-\bar{\theta}) \ln p_{t+1}^{*}+\lambda \tau_{t}^{W}\right\} \\
\text { s.t. } \quad I_{t}^{E}=p_{t} \bar{n}\left(1-\tau_{t}^{W}\right) \quad I_{t}^{U}=\frac{1}{1-q_{t}}\left[p_{t} \bar{n} \tau_{t}^{W} q_{t}+\Delta_{t}^{W}\right]
\end{gathered}
$$

where $\lambda$ is the multiplier associated with $\tau_{t}^{W} \geq 0$. In this optimization problem the home government recognizes the effect of its policies on the equilibrium prices.

The market clearing condition, (39), can be written as

$$
1=\bar{\theta} \frac{I_{t}}{D_{t}}+(1-\bar{\theta}) \frac{I_{t}^{*}}{D_{t}} \quad 1=\bar{\theta} \frac{I_{t}^{*}}{D_{t}^{*}}+(1-\bar{\theta}) \frac{I_{t}}{D_{t}^{*}}
$$

where $D_{t}\left(D_{t}^{*}\right)$ is $p_{t+1} q_{t+1} \bar{n}\left(p_{t+1}^{*} q_{t+1}^{*} \bar{n}\right), I_{t}=q_{t} I_{t}^{E}+\left(1-q_{t}\right) I_{t}^{U}$ and $I_{t}^{*}=q_{t} I_{t}^{* E}+\left(1-q_{t}\right) I_{t}^{* U}$. Using these market clearing conditions, the derivatives of prices with respect to the transfers are

$$
\frac{\frac{\partial p_{t+1}}{\partial \Delta_{t}^{W}}}{p_{t+1}}=\frac{\frac{1-q_{t}}{q_{t+1}} \frac{\bar{\theta}}{\bar{n}}}{p_{t+1}}=\frac{\bar{\theta}}{D_{t}} \quad \frac{\frac{\partial p_{t+1}^{*}}{\partial \Delta_{t}^{W}}}{p_{t+1}^{*}}=\frac{\frac{1-q_{t}^{*} \bar{\theta}}{q_{t+1}^{*}} \overline{\bar{n}}}{p_{t+1}^{*}}=\frac{(1-\bar{\theta})}{D_{t}^{*}} .
$$

The effect of tax rate variations on prices is zero since spending is independent of the distribution of income within a country.

Using these results, the two first-order conditions for the home government are

$$
\begin{aligned}
-\frac{q_{t} p_{t} \bar{n}}{I_{t}^{E}}+\frac{\left(1-q_{t}\right) p_{t} \bar{n} \frac{q_{t}}{1-q_{t}}}{I_{t}^{U}}+\lambda & =0 \\
\frac{1}{I_{t}^{U}}-\left(\frac{\bar{\theta}^{2}}{D_{t}}+\frac{(1-\bar{\theta})^{2}}{D_{t}^{*}}\right) & =0 .
\end{aligned}
$$

With $\bar{\theta}=1 / 2,(88)$ implies $D_{t}=D_{t}^{*}$ for all $t$. Further, these conditions imply that

$$
D_{t}+D_{t}^{*}=I_{t}+I_{t}^{*}
$$

Using (90) and the analogous condition for the foreign country,

$$
I_{t}^{U}=I_{t}^{* U}>D_{t}
$$


since $\bar{\theta}^{2}+(1-\bar{\theta})^{2}<1$. Hence, for (91) to hold,

$$
I_{t}^{E}<D_{t} \quad \text { and } \quad I_{t}^{* E}<D_{t}^{*}
$$

This implies that the employed in each country have lower nominal income than the unemployed. Thus in order for (89) to hold, as well as the analogous condition for the foreign country, $\lambda>0$ and $\lambda^{*}>0$. So, tax rates must be zero in both countries.

Because $\tau_{t}$ and $\tau_{t}^{*}$ are equal to 0 , given the definitions of the monetary transfers, and $\bar{\theta}=1 / 2$, the first order conditions with respect to $\Delta_{t}^{W}$ and $\Delta_{t}^{* W}$ simplify to

$$
\begin{aligned}
& \frac{1-q_{t}}{\Delta_{t}^{W}}-\frac{1}{4}\left[\frac{1}{q_{t+1} \bar{n} p_{t+1}}+\frac{1}{q_{t+1}^{*} \bar{n} p_{t+1}^{*}}\right]=0 \\
& \frac{1-q_{t}^{*}}{\Delta_{t}^{* W}}-\frac{1}{4}\left[\frac{1}{q_{t+1} \bar{n} p_{t+1}}+\frac{1}{q_{t+1}^{*} \bar{n} p_{t+1}^{*}}\right]=0 .
\end{aligned}
$$

The market clearing conditions are

$$
\begin{aligned}
& p_{t+1} q_{t+1} \bar{n}=E_{\theta, \theta^{*}}\left\{q_{t} \theta I_{t}^{E}+\left(1-q_{t}\right) \theta I_{t}^{U}+q_{t}^{*}\left(1-\theta^{*}\right) I_{t}^{* E}+\left(1-q_{t}^{*}\right)\left(1-\theta^{*}\right) I_{t}^{* U}\right\} \\
& p_{t+1}^{*} q_{t+1}^{*} \bar{n}=E_{\theta, \theta^{*}}\left\{q_{t}^{*} \theta I_{t}^{* E}+\left(1-q_{t}^{*}\right) \theta I_{t}^{* U}+q_{t}(1-\theta) I_{t}^{E}+\left(1-q_{t}\right)(1-\theta) I_{t}^{U}\right\} .
\end{aligned}
$$

When $\bar{\theta}=1 / 2$, these become

$$
p_{t+1} q_{t+1} \bar{n}=p_{t+1}^{*} q_{t+1}^{*} \bar{n}=\frac{1}{2}\left[M_{t}+\Delta_{t}^{W}+\Delta_{t}^{* W}\right]
$$

The first-order conditions for the national governments' problems can be written

$$
\frac{1-q_{t}}{\Delta_{t}^{W}}=\frac{1}{2} \frac{1}{q_{t+1} \bar{n} p_{t+1}} \quad \frac{1-q_{t}^{*}}{\Delta_{t}^{* W}}=\frac{1}{2} \frac{1}{q_{t+1} \bar{n} p_{t+1}} .
$$

This implies

$$
\Delta_{t}^{W}=2\left(1-q_{t}\right) \cdot \frac{1}{2}\left[M_{t}+\Delta_{t}^{W}+\Delta_{t}^{* W}\right]
$$

Finally we get reaction functions

$$
\Delta_{t}^{W}=\frac{1-q_{t}}{q_{t}} \cdot\left[M_{t}+\Delta_{t}^{* W}\right] \quad \Delta_{t}^{* W}=\frac{1-q_{t}^{*}}{q_{t}^{*}} \cdot\left[M_{t}+\Delta_{t}^{W}\right]
$$

The Nash equilibrium of the game is then given by the following:

$$
\Delta_{t}^{W}=\frac{1-q_{t}}{q_{t}+q_{t}^{*}-1} \cdot M_{t} \quad \Delta_{t}^{* W}=\frac{1-q_{t}^{*}}{q_{t}+q_{t}^{*}-1} \cdot M_{t}
$$

This completes the proof as $2 D_{t-1}=M_{t}$.

Proposition 7.. If the variability of the taste shock is sufficiently small and $\bar{q}$ and $\bar{q}^{*}$ are 
sufficiently below 1 , then $V_{W}<V_{F}$. If $\bar{q}$ and $\bar{q}^{*}$ are near 1 and the variability of taste shocks is large enough, then $V_{W}>V_{F}$.

Proof. Suppose that the variance of $\theta$ is 0 and $\bar{q}$ and $\bar{q}^{*}$ are below 1 . Recall that in this case, $V_{F}=V_{S}$ : welfare in the multiple currency environment is the same as that obtained in a strong monetary union. In the weak monetary union regime, consider a policy for each national government which equates the incomes of employed and unemployed agents. For the home country, if the period $t$ deficit is set at $\left(1-q_{t}\right) D_{t-1} / q_{t}$, then the income of a representative, generation $t$ unemployed agent will be $p_{t} \bar{n}$, the same as an employed generation $t$ agent. But, Proposition 6 implies that the equilibrium deficit is higher than $\left(1-q_{t}\right) D_{t-1} / q_{t}$ so that, as shown in the proof of that proposition, $I_{t}^{E}<I_{t}^{U}$. Therefore risks are not shared efficiently, and the equilibrium expected utility is less than $V_{S}$. Hence, $V_{F}>V_{W}$. By continuity, $V_{F}>V_{W}$ if the variance of $\theta$ is sufficiently small.

If $\bar{q}$ and $\bar{q}^{*}$ are equal to 1 and the variability of taste shocks is positive, then by Proposition 6 neither country runs a deficit. Because the money supply is constant, $V_{W}=V_{S}$. But, due to the taste shocks, $V_{S}>V_{F}$ from Proposition 5 so that $V_{W}>V_{F}$. By continuity, this holds if $\bar{q}$ and $\bar{q}^{*}$ are near 1 . 